\title{
SUPERPLASTIC PROPERTIES OF ALLOY 718
}

\author{
M.W. Mahoney \\ Rockwell International Science Center \\ Structural Materials Department \\ Thousand Oaks, California USA
}

\begin{abstract}
Alloy 718 , by its very design as a high-temperature, high-strength alloy, does not readily lend itself to conventional fabrication practices. Accordingly, innovative approaches have been developed over the years to facilitate economical fabrication of parts from Alloy 718. Now, a new method, superplastic forming (SPF), has emerged as a fabrication approach for materials difficult to work by other means. For this approach to be successful, metallurgical conditions of small grain size stable at the forming temperature must be met. This work shows that specially processed Alloy 718 (without alloy chemistry modification) can meet these requirements and accordingly can be superplastically formed into relatively complex-shaped geometries. Examples of the kinds of parts that can be superplastically formed are illustrated. In addition, the superplastic properties and characteristics of Alloy 718, including flow stress behavior, strain-rate sensitivity, cavitation and grain size stability are presented. Finally, microstructural changes that occur during SPF indicate that superplastic flow in Alloy 718 is controlled by dislocation motion and resulting dynamic recrystallization.
\end{abstract}




\section{Introduction}

Alloy 718 has found extensive use in high-temperature structural applications because of an advantageous combination of properties. However, costs of fabricating complex components remain high because of the difficulty to either machine or form this material via conventional fabrication procedures. This is evidenced by the large number of different approaches described in the literature to fabricate Alloy 718. Most recently, an additional approach, superplastic forming (SPF), has emerged as a possible manufacturing technique for difficult-to-fabricate materials, and other authors have noted the capability to achieve superplasticity even in Ni-base alloys (16).

Superplasticity is the ability of a material to resist nonuniform deformation and thus achieve large uniform strains under specific conditions of temperature and strain rate. Superplasticity in a widely used engineering alloy such as 718 could result in both reduced fabrication costs for components that are now fabricated by labor-intensive conventional practices, as well as new application areas that result from the fabrication of complex shapes not previously possible with Alloy 718. As with most fabrication processes, there are limitations, and SPF is not proported to be a substitute for all other manufacturing techniques. For example, SPF is limited to sheet products typically less than $2.5 \mathrm{~mm}(0.1 \mathrm{in}$.) thick. Also, for SPF purposes, the sheet must be specially processed to create a fine, stable grain size. However, if found to be superplastically formable, SPF of Alloy 718 could be added to the variety of fabrication practices now available.

This manuscript describes the extent to which superplasticity has been achieved in Alloy 718. Included are SPF properties of high-temperature flow stress behavior, strain-rate sensitivity, uniform elongation, and illustrations of the kinds of geometries that have been superplastically formed. Also, microstructural features of grain size stability and cavitation are presented, along with a discussion on possible mechanisms of superplastic flow in Alloy 718.

\section{Fine-Grain Alloy 718}

Fine grain Alloy 718 used in this study was specially fabricated to sheet thicknesses from $0.5 \mathrm{~mm}$ to $2.5 \mathrm{~mm}$ by the Huntington Division of INCO Alloys International. Grain size in the $0.5 \mathrm{~mm}$ sheet, as measured by the linear intercept technique, is less than $6 \mu \mathrm{m}$, Fig. 1. For thicker sheets, the grain size increases, reaching $\sim 8 \mathrm{~m}$ at $2.5 \mathrm{~mm}$ thick. Notice in Fig. I the grain shape is equiaxed in all three planes, an important requirement for superplasticity. Fabrication procedures to produce the very fine-grain size are proprietary to INCO Alloys and, as such, are not presented in this paper. Nominal composition of this heat of Alloy 718 is listed in Table I. Chemistry modifications were not necessary to produce the fine microstructure. This allows direct use of the material in existing applications without extensive qualification testing.

Table I. Chemical Composition of Alloy 718 (wt. pct)

\begin{tabular}{|rccccccc|}
\hline $\mathrm{Ni}$ & $\mathrm{Cr}$ & $\mathrm{Nb}+\mathrm{Ta}$ & $\mathrm{Mo}$ & $\mathrm{Ti}$ & $\mathrm{Al}$ & $\mathrm{C}$ & $\mathrm{Fe}$ \\
\hline 53.44 & 18.92 & 5.10 & 2.99 & 0.93 & 0.46 & 0.03 & 18.13 \\
\hline
\end{tabular}




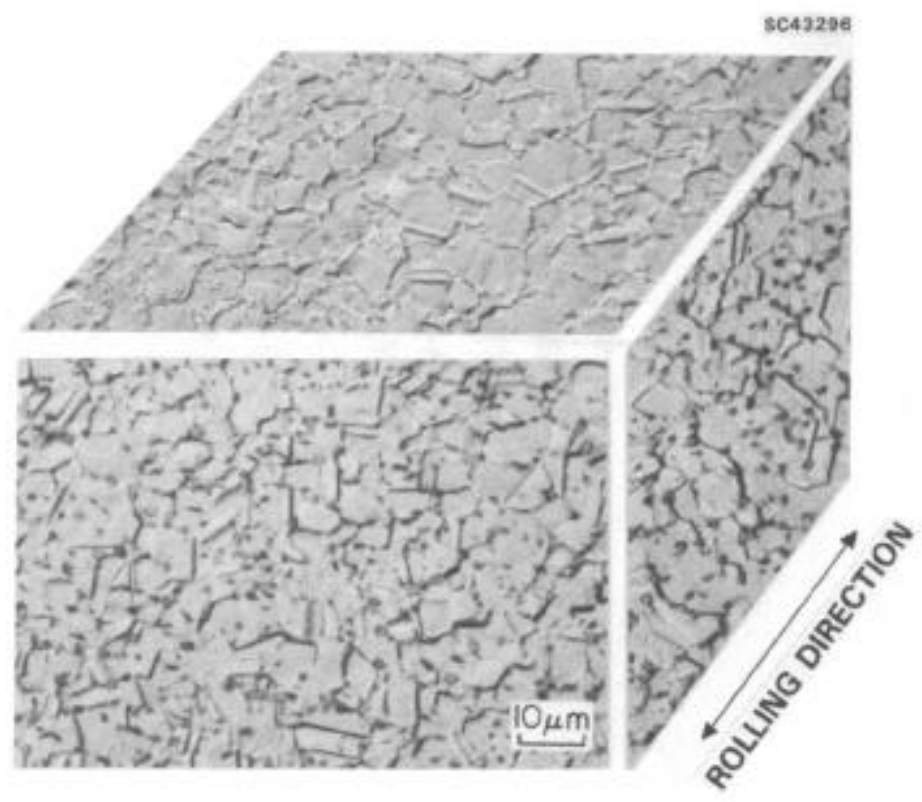

Fig. 1 Microstructure of Alloy 718 specially processed to a fine grain size $(<6 \mu \mathrm{m})$.

\section{Superplastic Characterization}

Evaluation of superplasticity was conducted by determining flow stress over a strain rate range of $5 \times 10^{-5}$ to $5 \times 10^{-4} \mathrm{~s}^{-1}$ at $982^{\circ} \mathrm{C}$ in a manner as originally proposed by Backofen et al (7). Superplastic flow characteristics were determined by step strain-rate tests, whereby strain rate was incrementally increased each time the load reached a maximum. From these kinds of data, a measure of the strain-rate sensitivity of the flow stress is defined by the strain-rate sensitivity exponent, $\mathrm{m}$, where $\mathrm{m}=\delta$ ino/ $\delta$ in $\dot{\varepsilon}$ resulting from the relation $\sigma=K \dot{\varepsilon}$, where $\sigma$ is the flow stress and $\dot{\varepsilon}$ is the strain rate. In addition, $\mathrm{m}$ values were determined as a function of strain by periodically increasing the strain rate by $40 \%$, establishing the flow stress, and again returning to the original strain rate. This type test, where $\mathrm{m}$ is shown to change with increasing strain, is a reasonable simulation of changes that occur during SPF.

Although it can be determined by several methods, $\mathrm{m}$ is simply a computed value describing the relationship between the flow stress and strain rate. Further, $m$ is not a constant, but varies with strain and strain rate and is descriptive of the strainrate sensitivity of flow stress over only a small, finite variation of strain rate. The relative values of strain rate at a local stress concentration as compared to other locations ultimately determine the material's response to plastic instability.

Tensile specimens of each material were also pulled to failure in uniaxial tension at constant strain rates to determine total elongation and work-hardening characteristics. For all uniaxial tests, specimens of the conventional dogbone shape having a gauge length of $0.64 \mathrm{~cm}$ were tested in tension at a constant (true) strain rate. An Instron machine was modified such that the cross-head velocity could be automatically adjusted as the specimen elongates to maintain an approximately constant strain rate.

\section{Superplastic Properties}

Using the SPF testing approach described above, flow stresses, at a strain rate of $5 \times 10^{-4} / \mathrm{s}$ and test temperatures of $982^{\circ} \mathrm{C}$ and $1010^{\circ} \mathrm{C}$, were established for Alloy 718. Figures 2 and 3 illustrate flow behavior for both the longitudinal and transverse orientations as well as indications of total elongations to failure. There are notable differences in material response at these two temperatures. At the higher temperature of $1010^{\circ} \mathrm{C}$, elongations are approximately half those measured at $982^{\circ} \mathrm{C}$. This 


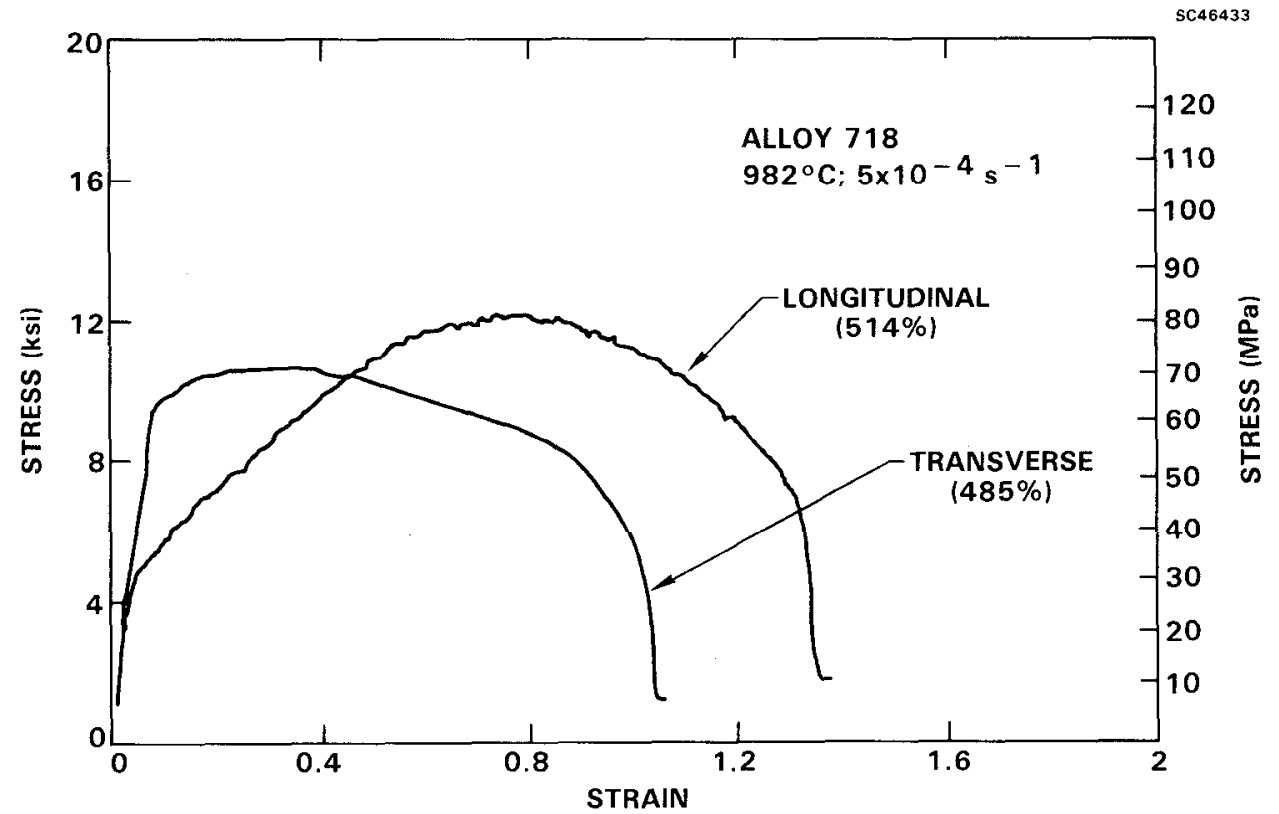

Fig. 2 Flow stress behavior of Alloy 718 at $982^{\circ} \mathrm{C}$ for both longitudinal and transverse orientations.

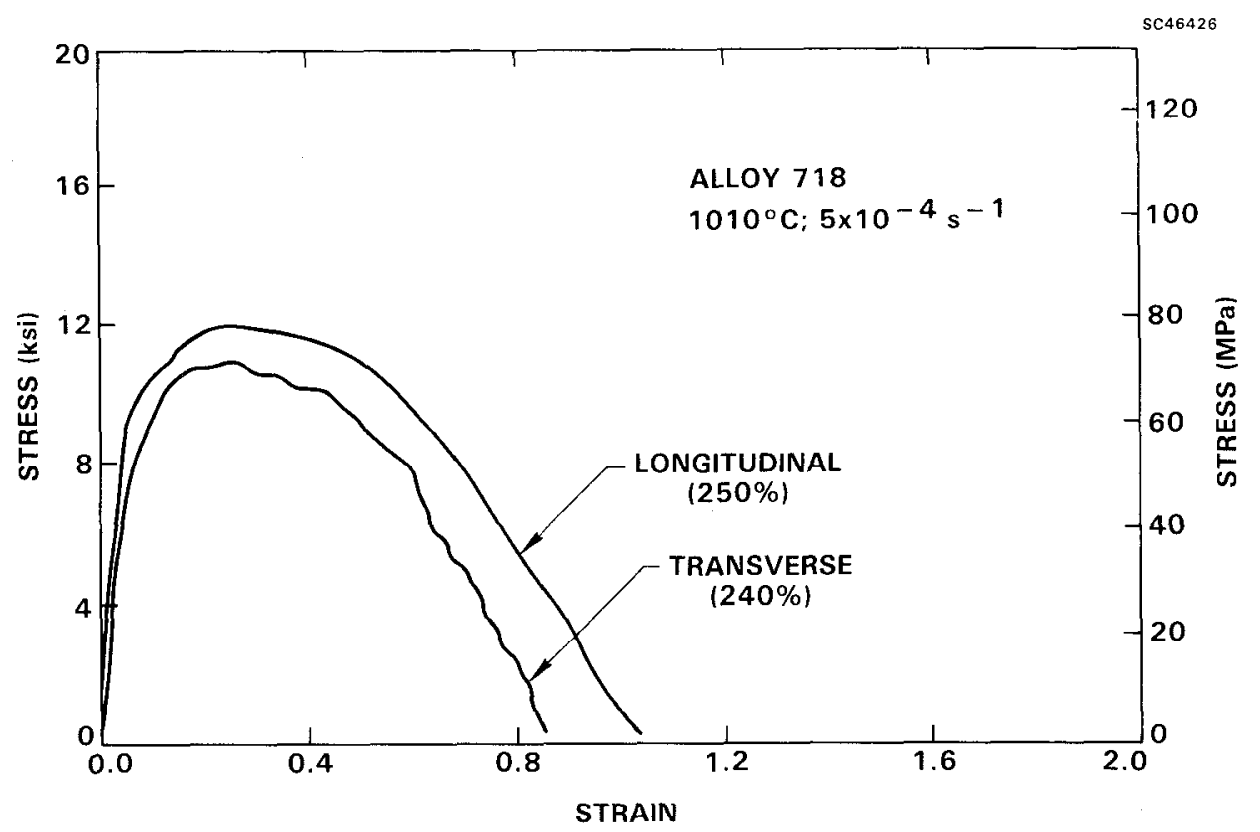

Fig. 3 Flow stress behavior of Alloy 718 at $1010^{\circ} \mathrm{C}$ for both longitudinal and transverse orientations.

reduced resistance to elongation is shown below to be associated with grain growth. Also, elongations are consistently less in the transverse orientation than in the longitudinal. It is possible that this anisotropic behavior is caused by carbide stringers in the rolling direction, creating sites for premature failure in the transverse samples.

From a practical forming perspective, Figs. 2 and 3 show the maximum flow stress to approach $80 \mathrm{MPa}(12 \mathrm{ksi})$. The higher the flow stress, the more difficult the forming operation because of corresponding higher pressures necessary for metal flow. Thus, the flow stress should be kept as low as possible to facilitate forming, however, 
fur ther increases in temperature reduce elongations. Although not shown here, similar tests at lower temperatures $\left(954^{\circ} \mathrm{C}\right)$ yield even lower elongations $(110 \%)$ and higher flow stresses $(100 \mathrm{MPa})$. This results in a relatively narrow temperature range over which Alloy 718 can be considered practical for SPF.

As discussed above, grain growth at temperatures above $982^{\circ} \mathrm{C}$ is the major contributor to reduced elongations $\left(540 \%\right.$ at $982^{\circ} \mathrm{C}$ vs $240 \%$ at $\left.1010^{\circ} \mathrm{C}\right)$. Figures 4 and 5 illustrate differences in grain stability for these two test temperatures. Clearly, even static grain growth is very rapid at $1010^{\circ} \mathrm{C}$, while at $982^{\circ} \mathrm{C}$ the grain morphology is stable. A second consideration concerning grain stability is dynamic grain growth, i.e., grain growth, at temperature while the sample is being strained. Dynamic grain growth at SPF temperatures can be considerably greater than that observed for static temperature exposures, and is made even more complicated by recrystallization during $\mathrm{SPF}$. This subject is addressed in greater detail in the superplastic mechanisms section of this paper.

Strain-rate sensitivity, the measure of resistance to nonuniform flow, for this fine grain Alloy 718 is illustrated in Fig. 6. Alloy 718 does not exhibit the classical sigmoidal-shaped stress/strain-rate type behavior, but instead, the curves are relatively flat as compared to highly superplastic materials. Strain-rate sensitivity or mvalue, for this material at $982^{\circ} \mathrm{C}$ is therefore moderate, 0.5 , and resistance to necking is limited. Also, based on these results, no clear indication of an optimum strain rate is evident. The useful strain-rate range is broad, with strain rates from $5 \times 10^{-5} / \mathrm{s}$ to $5 \times 10^{-4} / \mathrm{s}$.

Another useful measure of superplasticity is strain-rate sensitivity as a function of strain. From these data, the change in necking resistance during forming can be followed. This is shown as a function of three strain rates in Figs. 7-9. Each figure shows a rapid increase in flow stress with increasing strain, with the higher stresses corresponding to the faster strain rates. Strain rates of 1 to $2 \times 10^{-4} / \mathrm{s}$ offer a reasonable balance between time of forming and magnitude of gas pressure, i.e., higher strain rates increase forming pressure requirements, and lower strain rates increase forming times.
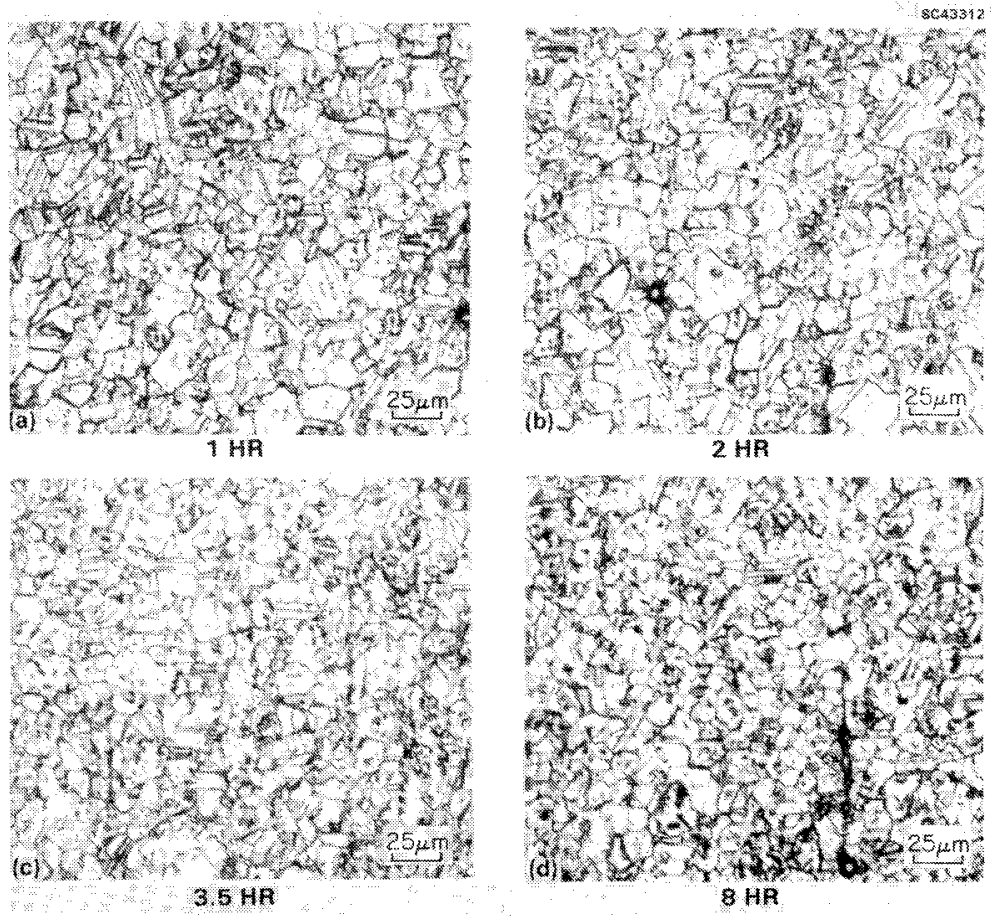

Fig. 4 Static grain growth in Alloy 718 at $982^{\circ} \mathrm{C}$. 

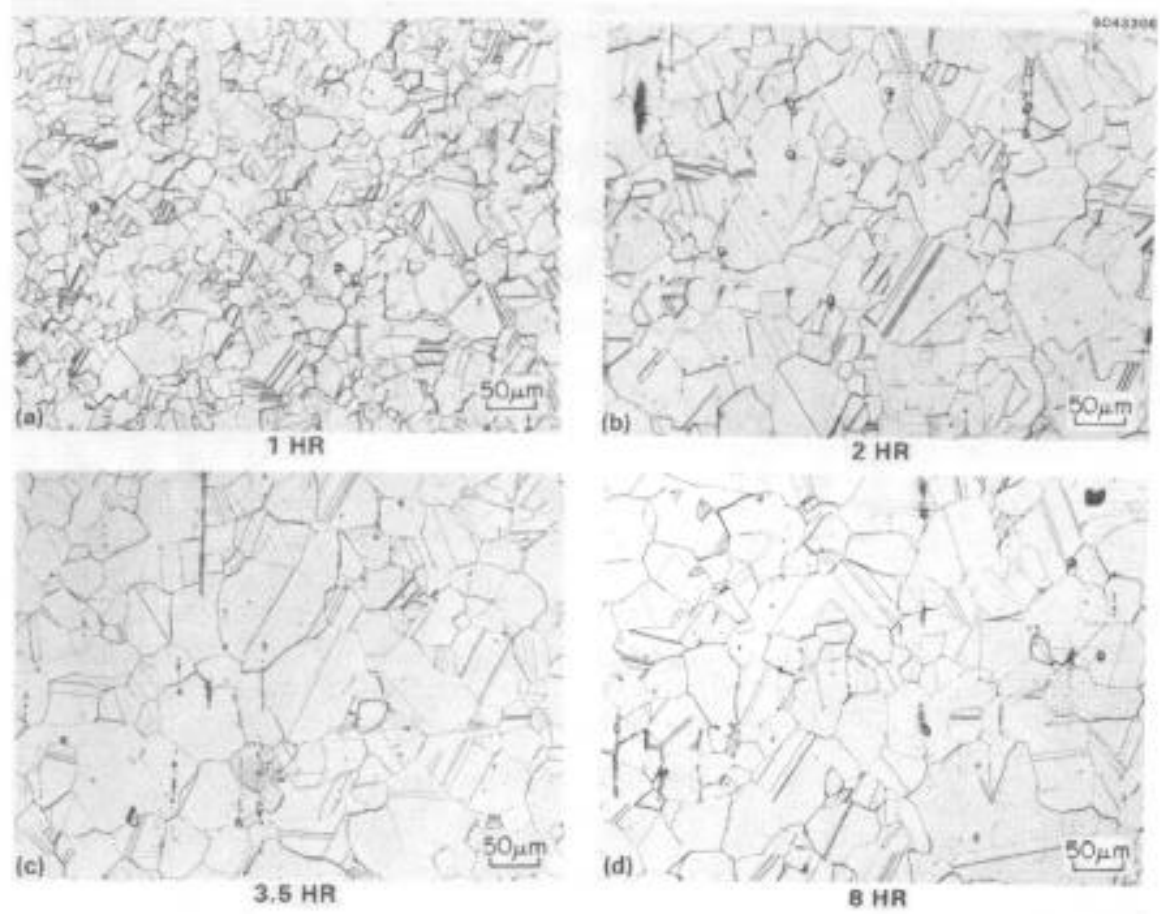

Fig. 5 Static grain growth in Alloy 718 at $1010^{\circ} \mathrm{C}$.

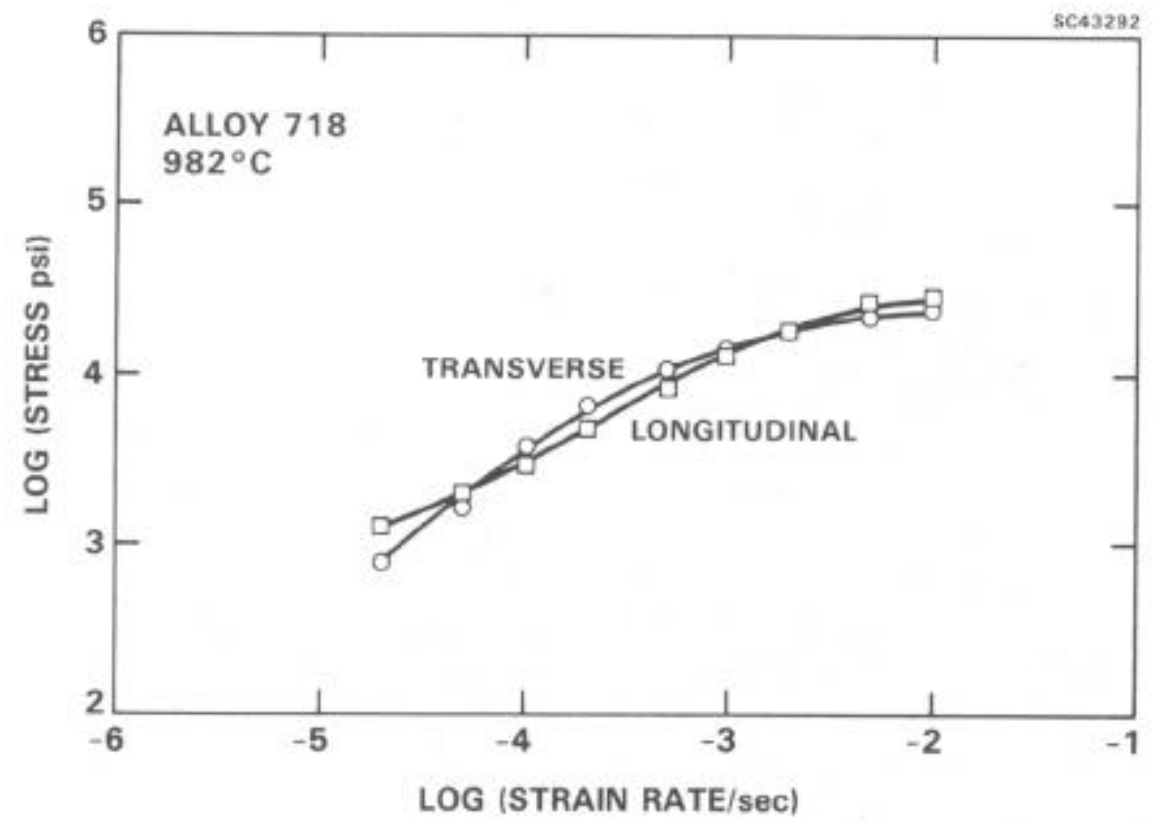

Fig. 6 Strain-rate sensitivity of Alloy 718 at $982^{\circ} \mathrm{C}$ for transverse and longitudinal orientations. 
More importantly, Figs. 7-9 illustrate a rapid decline in the strain-rate sensitivity index $m$ with increasing strain. A decline in necking resistance with accumulated strain is common, but for highly superplastic materials this decline is gradual. The rapid decline in $m$ observed here would indicate limited superplasticity for Alloy 718 . A reduced rate of decline would be beneficial for forming.

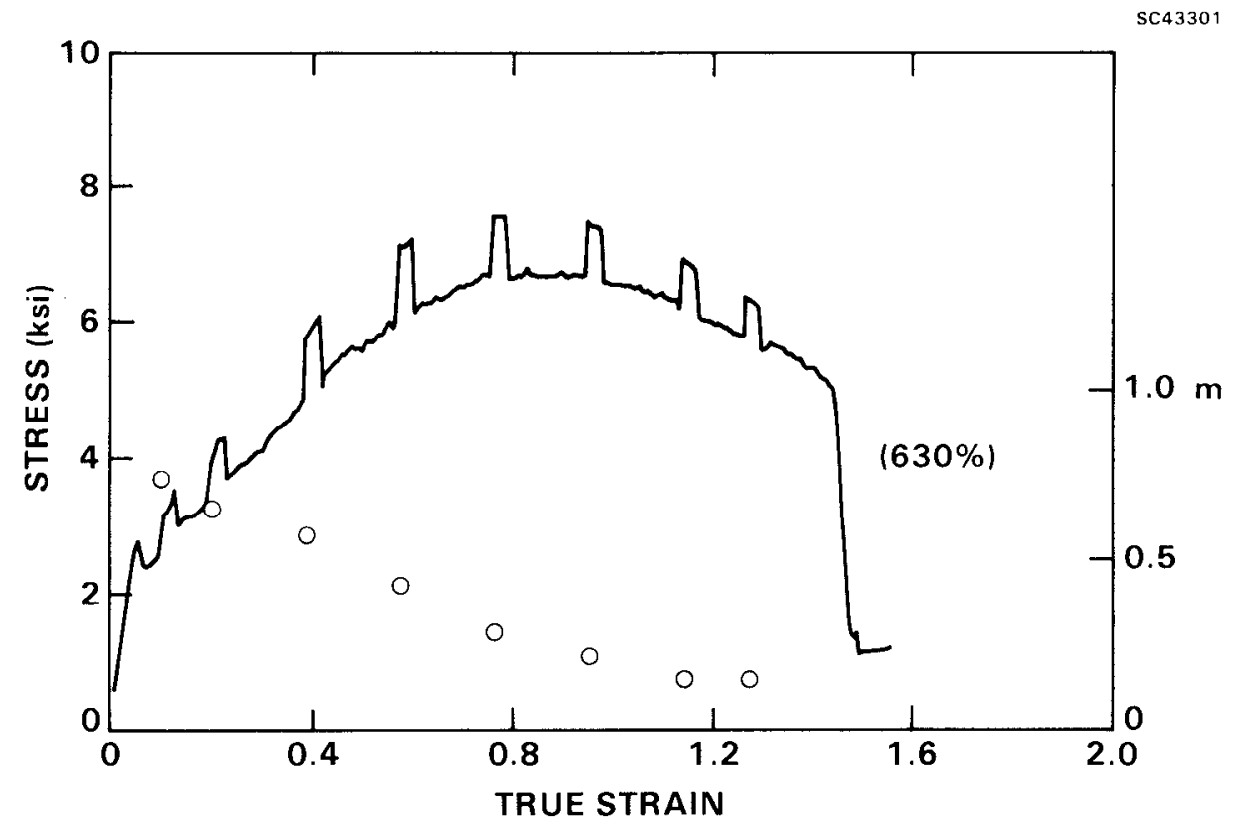

Fig. 7 Strain-rate sensitivity of Inconel 718 with increasing strain at a strain rate of $5 \times 10^{-5} \mathrm{~s}^{-1}$.

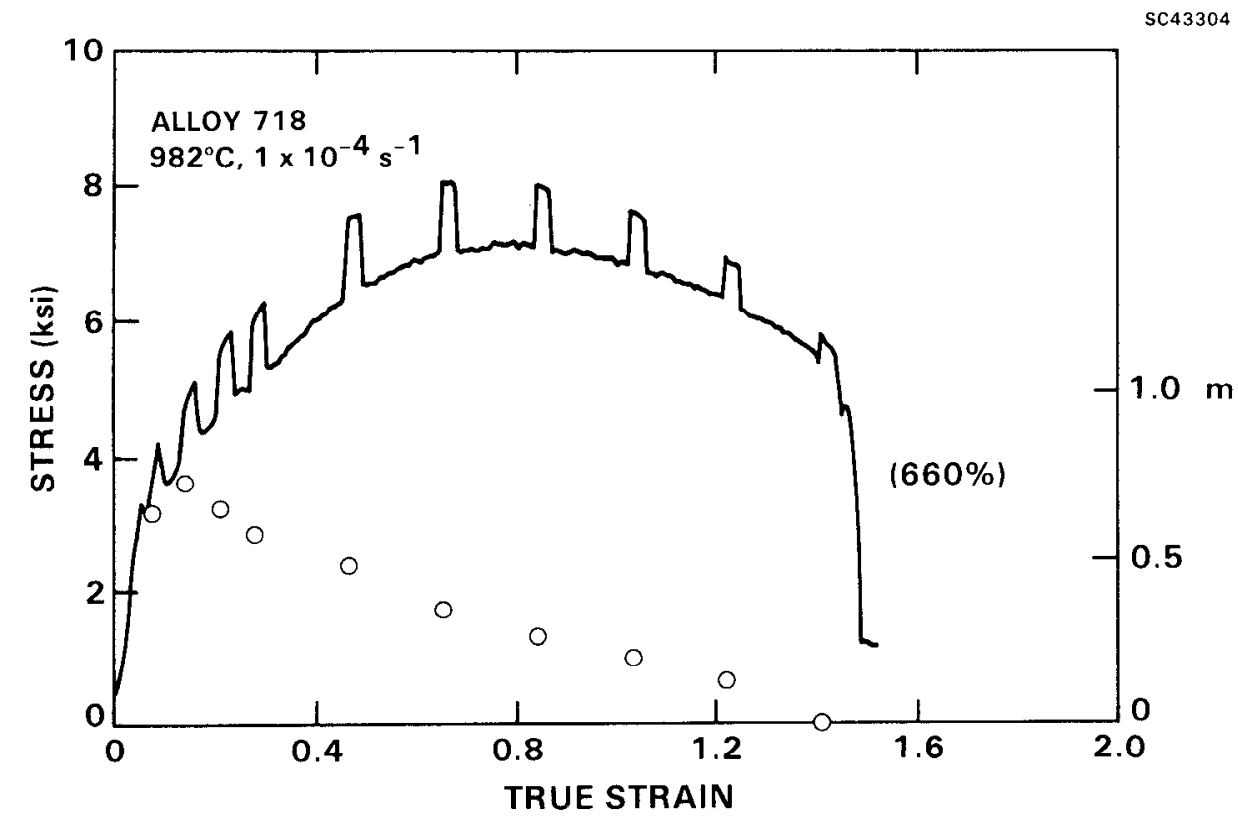

Fig. 8 Strain-rate sensitivity of wrought fine grain 718 with increasing strain at a strain rate of $1 \times 10^{-4} \mathrm{~s}^{-1}$. 


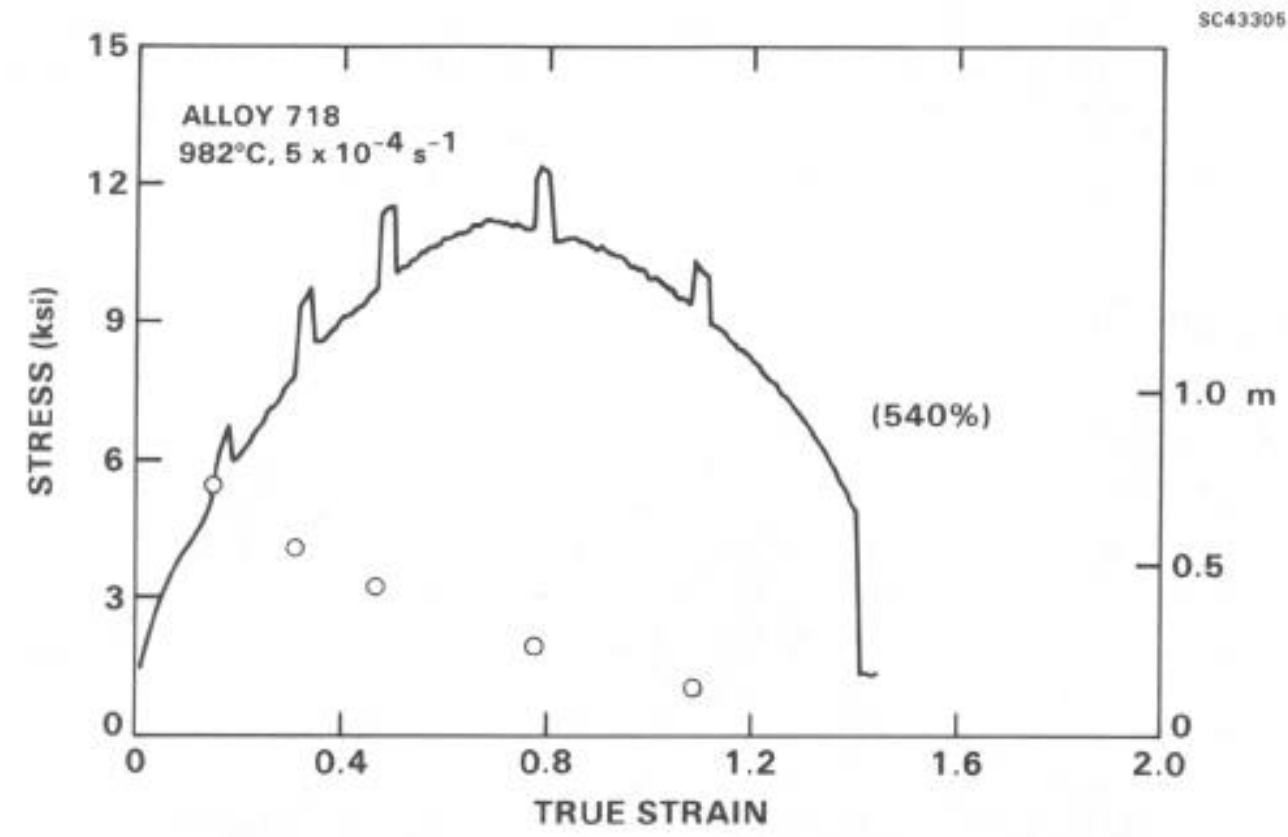

Fig. 9 Strain-rate sensitivity of wrought fine grain 718 with increasing strain at a strain rate of $5 \times 10^{-4} \mathrm{~s}^{-1}$.

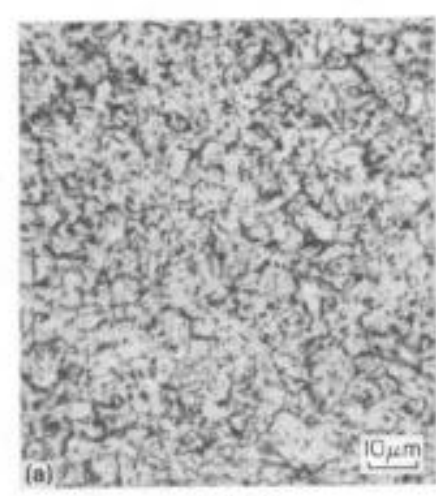

GRIP

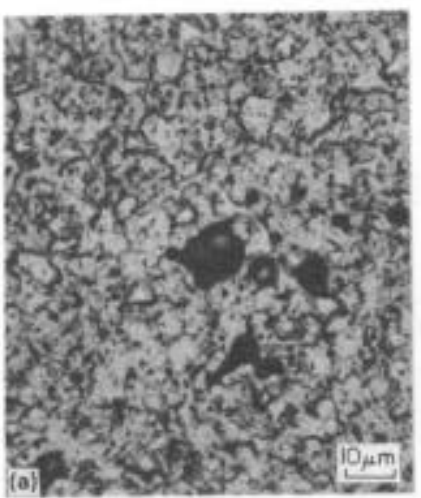

$c_{\mathrm{t}}=1.3$

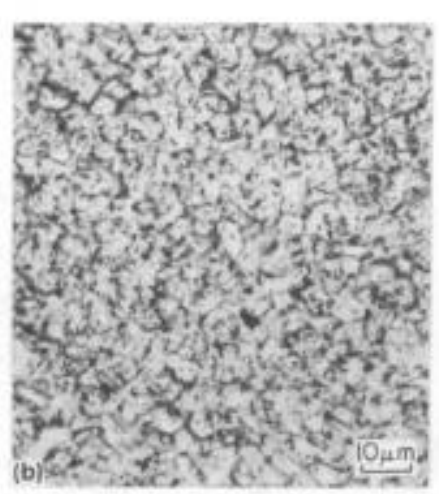

$\varepsilon_{\mathrm{t}}=0.45$

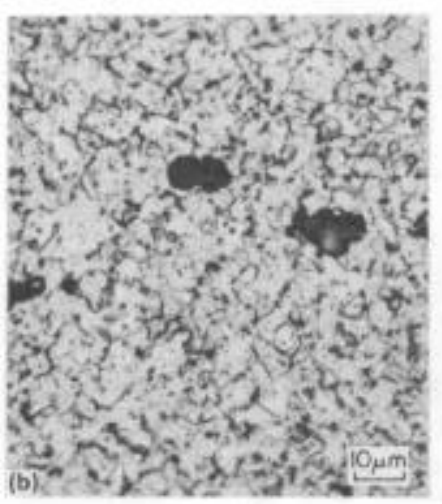

$c_{t}=1.8$

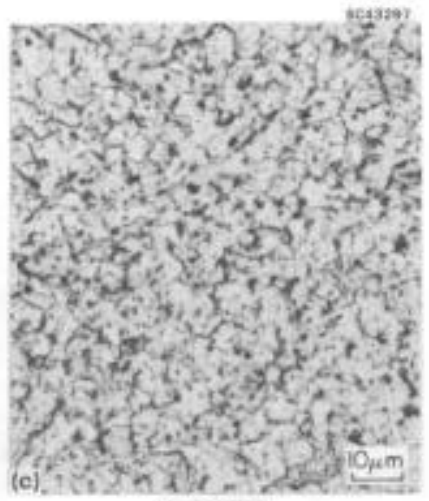

$\varepsilon_{\mathrm{t}}=0.86$

scesas

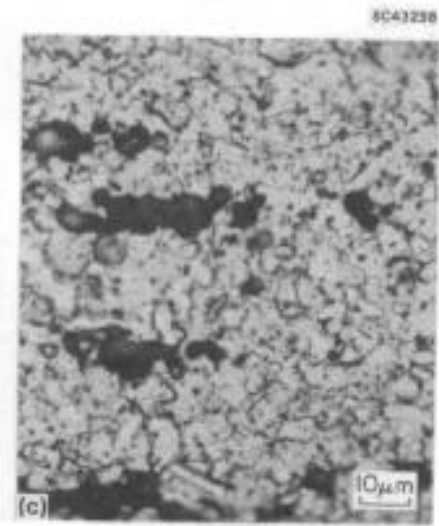

$c_{t}=2.5$

Fig. 10 Microstructure of Inconal 718 with increasing superplastic strain $\left(982^{\circ} \mathrm{C}, 5 \mathrm{x}\right.$ $10^{-4} \mathrm{~s}^{-1}$. 
Another observation concerning strain-rate sensitivity is the identical rate of decline observed in $\mathrm{m}$ for the three strain rates. To achieve equivalent strains at strain rates of $5 \times 10^{-5} / \mathrm{s}$ vs $5 \times 10^{-4} / \mathrm{s}$ would require an order of magnitude difference in time. However, the rate of decline in $\mathrm{m}$ at these two strain rates is identical. $\mathrm{m}$ does not appear to be sensitive to time at temperature (at least at $982^{\circ} \mathrm{C}$ ), but is better related to total strain. This result is likely related to the dynamic recrystallization behavior later shown to occur during SPF.

Cavitation in some materials occurs during SPF with cavities increasing in size and frequency as the strain increases. For example, titanium alloys in general are immune to cavitation, but in Al alloys techniques such as "backpressure" must be used to suppress the onset of a stable pore. Unfortunately, Alloy 718 is not immune to cavitation; cavities do occur in Alloy 718 following a similar pattern of increased size and frequency with increasing strain. Figure 10 illustrates Alloy 718 tested at $982^{\circ} \mathrm{C}$ and $5 \times 10^{-4} / \mathrm{s}$ with increasing superplastic strain. For true strains up to 0.86 (135\%), cavities were not present. However, at a true strain of 1.3 (265\%), sizable cavities are evident with interlinkage of these cavities at higher true strains.

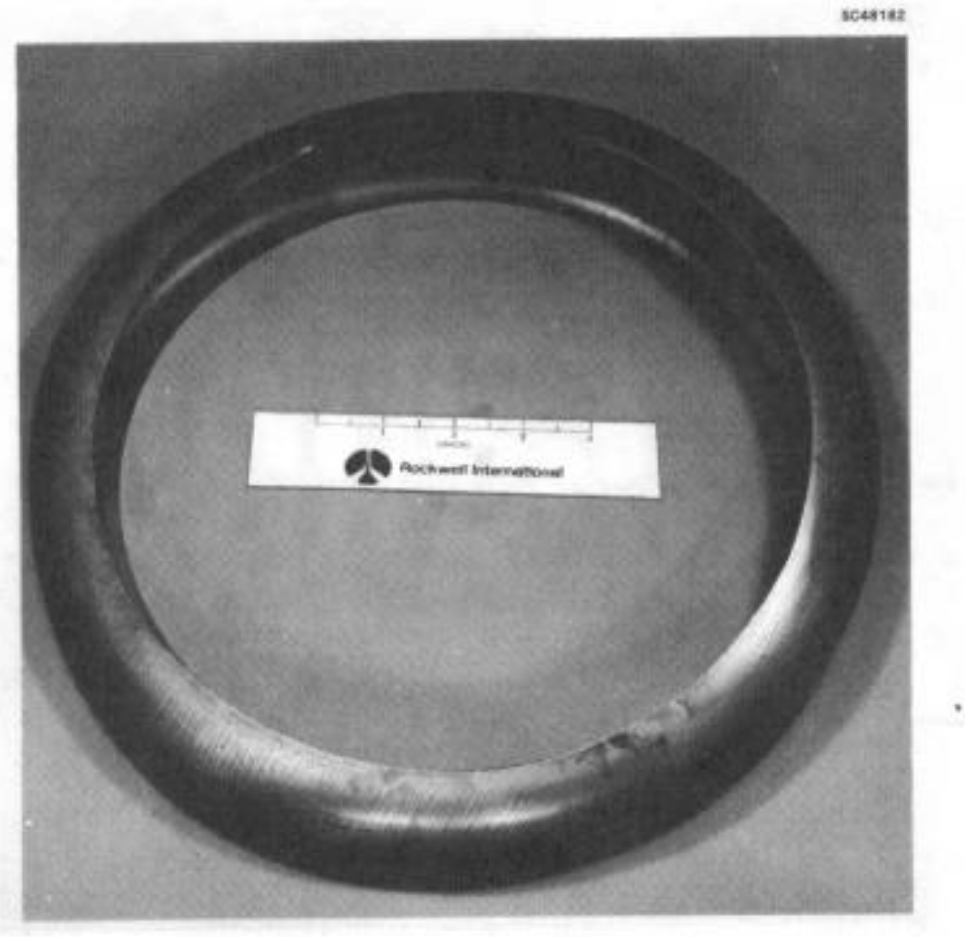

Fig. 11 Alloy 718 tested at $982^{\circ} \mathrm{C}$ and $5 \times 10^{-4} / \mathrm{s}$ with increasing superplastic strain.

Backpressure techniques commonly used to suppress cavitation during SPF of Al alloys would not be practical with Alloy 718 because of the higher flow stress. However, because cavities are gas-free, success has been reported with healing of cavities in $\mathrm{AI}$ alloys after SPF by hot isostatic pressing (8). It is possible that this approach would also be beneficial with Alloy 718 .

\section{Superplastically Formed Parts}

Superplastic forming of Alloy 718 is a new endeavor recently removed from the research laboratory; and at this time, no parts are in service fabricated by this process. However, demonstrations of the type of components that can be superplastically formed include a relatively thick $(2.5 \mathrm{~mm})$ half torus formed and subsequently welded to demonstrate fabrication of a Space Shuttle preoxidizer burner (Fig. 11); in another example, a generic shape was used to demonstrate the capability to form very thin sheets $(0.55 \mathrm{~mm})$ into complex shapes (Fig. 12). Thin sheet forming offers additional benefits of reduced weight. 


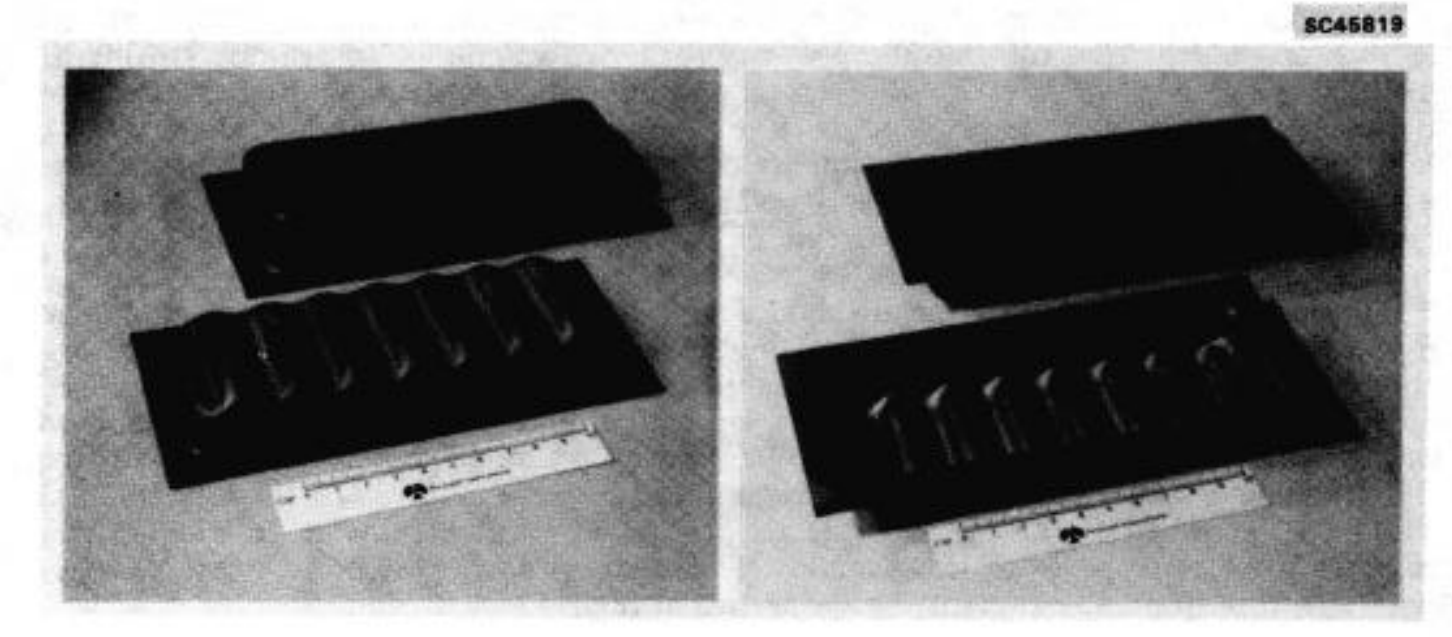

Fig. 12 Photographs of complex-shaped geometries superplastically formed with thin gauge $(0.55 \mathrm{~mm}$ thick) fine-grain Alloy 718 .

Both parts were made via typical SPF practices, i.e., sheet gas pressure formed into dies using predetermined gas pressure/time profiles to maintain a constant strain rate. For simple shapes, the pressure/time profile is calculated analytically with established computer programs. For the more complex geometries, curve-blending techniques are used whereby portions of different pressure/time profiles are selected to approximate different stages of the forming cycle.

Parts such as those shown above are typically formed in less than $1 \mathrm{~h}$ at pressures less than $6.9 \mathrm{MPa}(1000 \mathrm{psi})$. These pressures are sufficiently low to enable forming to be accomplished under reasonable work conditions without extraordinary precautions of high-pressure facilities. Also, the times for SPF for these complex shapes are short. Each of these conditions results in a manufacturing process that can be economical for selected geometries. The economical advantage of SPF is considerable when realizing the part is conventionally fabricated by machining the torus from a solid block of Alloy 718.

The Space Shuttle manifold shown in Fig. 11 was made by forming two halves of the torus and subsequently welding the two sections around the circumference. Forming was possible with only one die because of symmetry of the part and absence of springback or warpage associated with SPF. This lack of distortion after forming is one of the benefits attributable to the SPF process.

A second dimensional consideration is thinning of the formed sheet at highly strained regions and also where the sheet is required to draw over a die edge. Die friction effects can be minimized by providing generous edge radii and lubrication of the sheet surface with a high-temperature lubricant that will not react with Alloy 718 at the forming temperature $\left(982^{\circ} \mathrm{C}\right)$. Intrinsic thinning, i.e., thinning associated with strain in the sheet, can be reduced only by improving the strain-rate sensitivity of the material. However, even for the part shown in Fig. 11, variations in the reduction in sheet thickness ranged from only $12 \%$ to $19 \%$.

Using this same heat of Alloy 718, tests were performed to determine the effect SPF might have on mechanical properties. Since standard samples could not be machined from curved sections, samples had to be obtained from flat locations of a superplastically formed part. These locations have less accumulated strain than curved locations, but can at least illustrate a trend in effect on properties. For samples heat-treated to full strength following SPF, both yield and tensile strength were reduced approximately $14 \%$. 
Work needs to be performed to determine if this reduction in strength can be recovered by a modified heat treatment or perhaps by hot isostatic pressing (HIP) to reduce cavitation. Also, for high-temperature applications where creep strength would be of importance, Fig. 5 shows that, following forming, the grain size can be increased to more conventional grain sizes by aging at temperatures above $982^{\circ} \mathrm{C}$.

\section{Mechanisms of Superplastic Flow in Alloy 718}

There has been considerable controversy over the mechanisms of superplastic deformation, and over the past 20 years theories that attempt to describe superplastic metal flow in terms of either single or several deformation mechanisms have been proposed. The experimental evidence now indicates that several processes can occur during superplastic deformation, including grain boundary sliding, dislocation motion, diffusional processes and dynamic recrystallization. Because of the limited experimental information available on superplasticity of Alloy 718, the mechanisms controlling superplastic flow in this alloy are not especially well understood.

In this work, the $<6 \mu \mathrm{m}$ grain size Alloy 718 showed elongations to be relatively limited with an average true strain at fracture of $\sim 1.8$. Even at this low level of strain, necking occurred along the gauge length indicating only moderate strain rate sensitivity. This result is shown quantitatively in Figs. 7-9 where $\mathrm{m}$ is shown to decrease rapidly as a function of accumulated strain. This rapid decrease in strainrate sensitivity behavior is not characteristic of a highly superplastic material and indicates that a change in the controlling mechanism behavior is likely occurring early in the forming cycle.

Figure $13 a-g$ is a sequence of micrographs showing the effefts of increasing strain for a sample tested at $982^{\circ} \mathrm{C}$ and a strain rate of $1 \times 10^{-4} \mathrm{~s}^{-1}$. As shown, the initial grain size is small with an approximately equiaxed grain shape. With increasing strain, grains increase in size up to a true strain of $\sim 1.14$. At higher levels of strain, the grain size decreases reaching a minimum at a strain of $\sim 1.61$. At higher levels of strain, grains again increase in size and continue to increase up to fracture at a strain of 2.71. The grain shape remains essentially equiaxed throughout the test, but the micrograph in Fig. 13e shows a bimodal grain size distribution, indicating initiation of grain refinement.

A note concerning data collection is in order. It is not possible to quantitatively equate the results in Figs. 8 and 13 because of the different way the data were collected. Data in Fig. 13 were continuously and analytically derived during testing assuming uniform flow, i.e., no necking. These results illustrate an average true strain over the entire gauge length. Strain measurements from Fig. 8 were measured directly from the sample and accurately reflect the local level of strain for the microstructure shown at that precise location. Since necking did occur, Fig. 8 can be used only to illustrate a trend, i.e., true strains are higher than shown for a given value of $\mathrm{m}$.

In superplastic materials, grains commonly grow and elongate in the stress direction. This grain growth and shape change has been explained by diffusional processes whereby vacancies diffuse to grain boundaries approximately parallel to the tensile axis, with a corresponding counterflux of atoms to boundaries perpendicular to the tensile axis. Results illustrated in Fig. 13 show grain growth up to some intermediate level of strain, where grain refinement occurs, followed again by grain growth. Initial grain growth behavior can be explained by diffusional flow, but retention of an equiaxed grain structure and subsequent grain refinement can only be described as other mechanisms.

To explain an equiaxed grain shape and a reduction in grain size, other investigators have suggested that dynamic recrystallization can be an important component of superplastic deformation $(9,10)$. Dynamic recrystallization can occur in materials that have limited dislocation mobility and tend to develop localized, high dislocation 


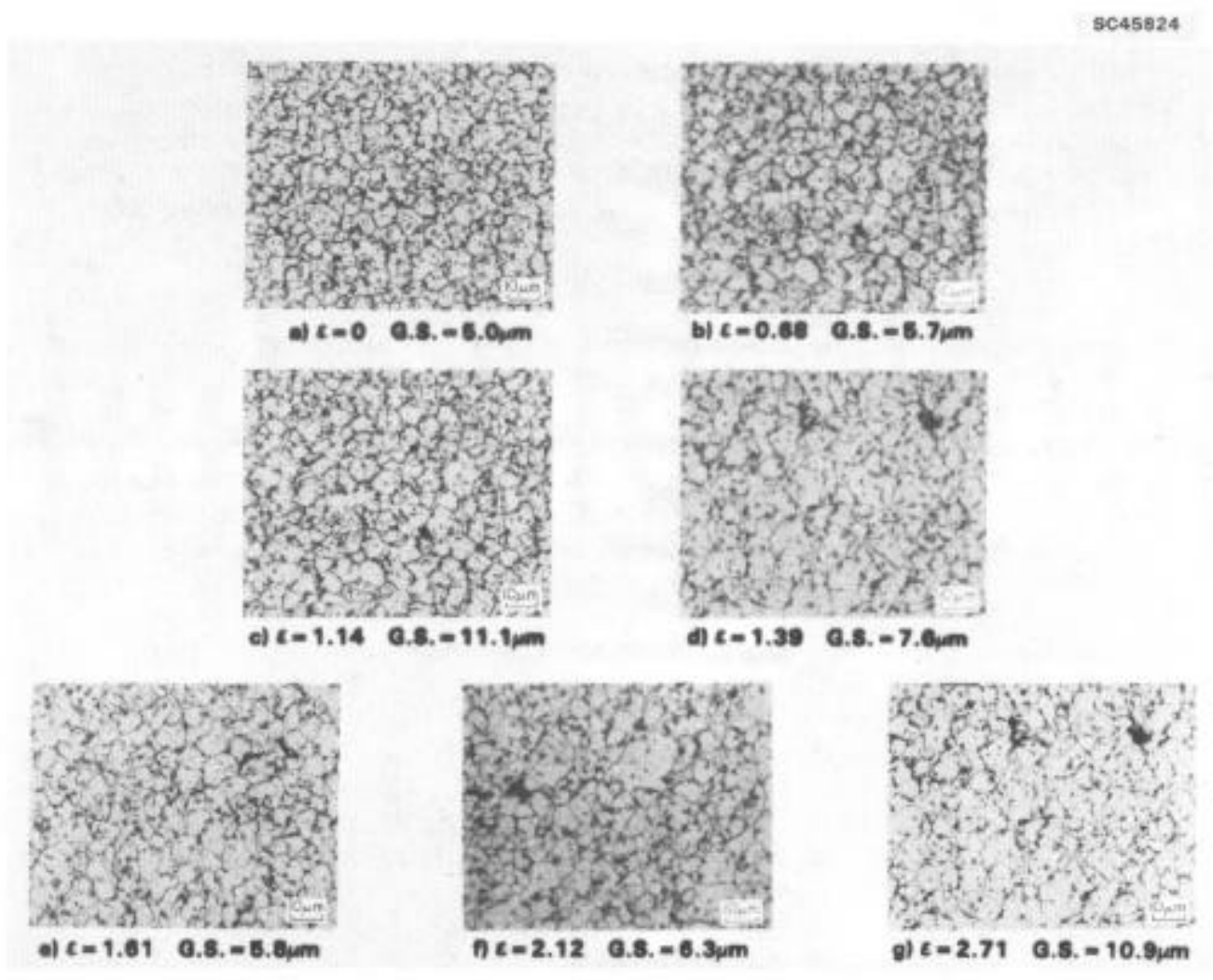

Fig. 13 Grain morphology changes with increasing strain in Alloy 718 during SPF.

densities during deformation. When local differences in dislocation density are sufficiently high, recrystallization proceeds by the migration of high angle boundaries. Results from the present study show that dynamic recrystallization is active during superplastic flow of Alloy 718. The TEM micrograph in Fig. 14a shows high angle boundaries of recrystallized grains bowed into the grain (on the lower left) which contains a relatively large number of dislocations. This is typical of dynamic recrystallization where dislocation densities drop to very low levels just behind moving boundaries.

Fur ther evidence for dynamic recrystallization is shown by comparing Figs. 14 and 15. Figure 15 illustrates grain boundary misorientation in as received Alloy 718 while Fig. 14 provides misorientations after a true strain of 1.63 . Figures $14 \mathrm{~b}$ and $15 \mathrm{~b}$ are schematics of the TEMs of Figs. 14a and 15a, quantitatively illustrating grain boundary misorientations at the grain boundaries. The change in grain boundary misorientation is illustrated in Figs. $14 \mathrm{C}$ and $15 \mathrm{c}$ by determining the grain boundary lineal fraction in the as-received and superplastically strained (1.63) material. The number of twin boundaries $\left(59\right.$ to $60^{\circ}$ ) decreases, but the increase in the number of low angle boundaries illustrates stored energy available for dynamic recrystallization.

Referring to Fig. 13, only the portion of the sample strained above $\sim 1.14$ true strain exhibited dynamic recrystallization. This can be explained by the results of Sakai and Jonas (11), who have shown that the strain required to initiate dynamic recrystallization in Alloy 718 is high $\left(0.7\right.$ at $\left.975^{\circ} \mathrm{C}\right)$, and to produce complete recrystallization is much higher than that for less heavily alloyed materials.

The above results have shown grain refinement (Fig. 13) and yet the strain rate sensitivity continues to decrease (Figs. 7-9). If recrystallized grain boundaries are high angle boundaries, then flow should again be controlled by diffusion with a corresponding increase in $\mathrm{m}$. This apparent inconsistency can possibly be explained in two ways. First, Ghosh and Raj suggest that a bimodal grain distribution in a polycrystal 


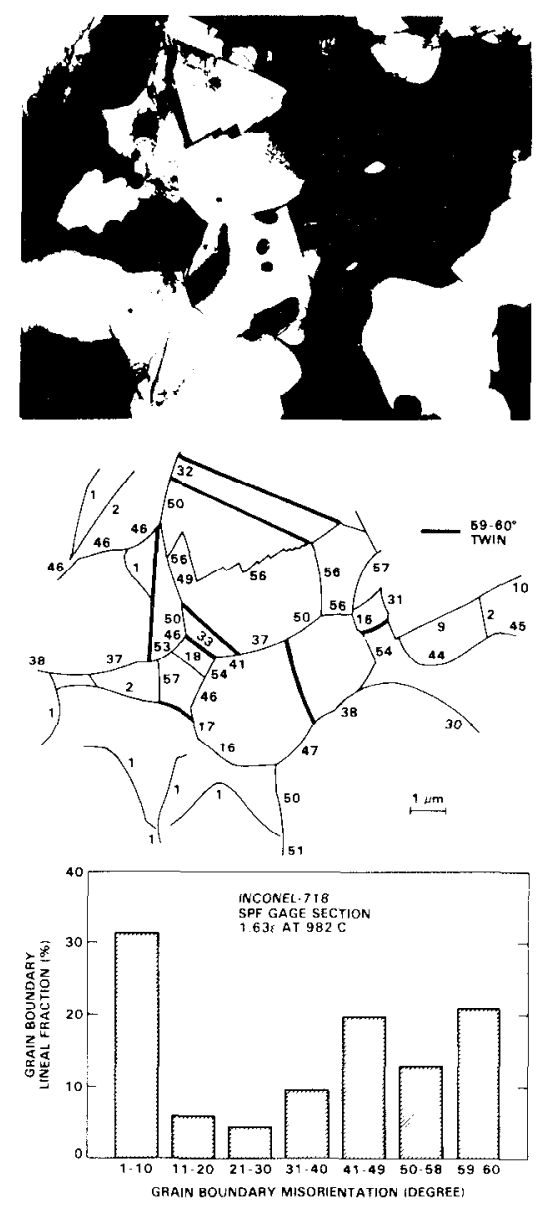

Fig. 14 Grain boundary misorientation distribution in SPF tested (1.63 true strain) Alloy 718: (a) original TEM micrograph; (b) schematic showing grain boundary misorientation; and (c) grain boundary lineal fraction for different misorientations.

such as shown in Fig. 13e can lead to mixed mode deformation (12). In this case, the microstructure may not be conducive to diffusion control because of the bimodal grain size and the increased number of small angle boundaries (compare Figs. 14 and 15). Another explanation could be the test procedure itself. Because of necking in the gauge, the sample is unable to reestablish a uniform strain rate. Thus, nonuniform strain continues even after grain refinement. If in fact superplasticity could be enhanced in-situ via dynamic recrystallization, then novel forming procedures might be developed to accumulate strain when the microstructure is most receptive to uniform elongations.

\section{Conclusions}

Alloy $718 \mathrm{can}$ be processed to sheet $(0.5 \mathrm{~mm}$ to $2.5 \mathrm{~mm}$ thick) with a fine grain size that remains stable up to tempertures of $982^{\circ} \mathrm{C}$. In addition, microstructural studies showed dynamic recrystallization to be active during superplastic flow at $982^{\circ} \mathrm{C}$. With this microstructure, Alloy 718 is moderately superplastic (400 to $500 \%$ strain) with a strain-rate sensitivity ( $m$ value) of $\sim 0.5$. With accumulated strain, strain-rate sensitivity rapidly decreases, limiting the extent of superplastic expansion with this alloy. However, even with this limitation, relatively complex-shaped parts could be superplastically formed from Alloy 718. 

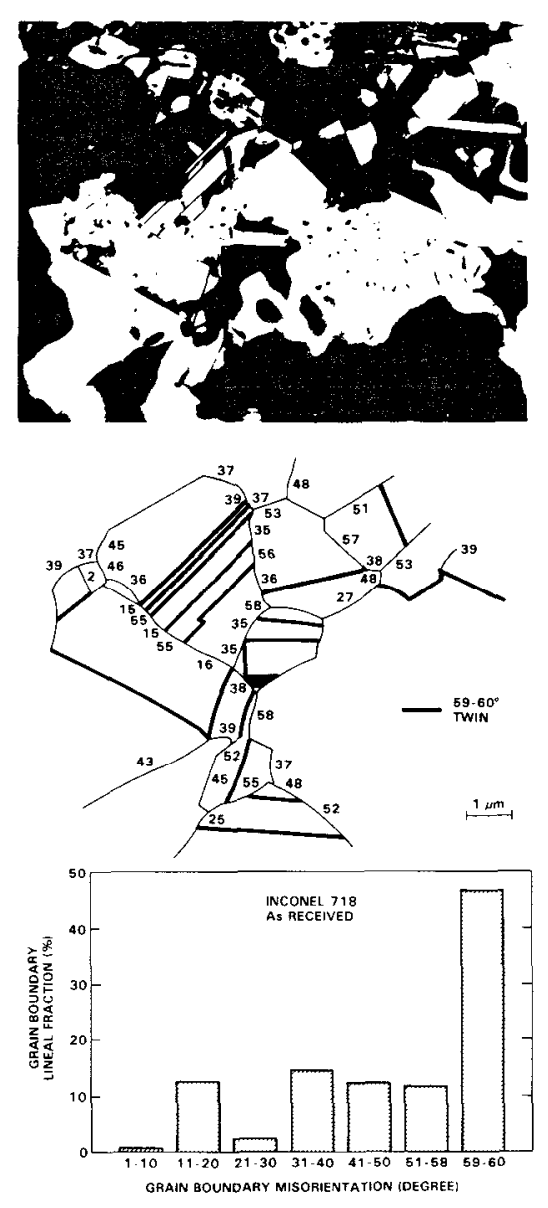

Fig. 15 Grain boundary misorientation distribution in as-received Alloy 718: (a) original TEM micrograph; (b) schematic showing grain boundary misorientation; and (c) grain boundary lineal fraction for different misorientations.

\section{Acknowledgements}

The author gratefully acknowledges the Air Force Flight Dynamics Laboratory, Contract No. F33615-86-C-3228, and Rockwell International IR\&D for joint funding of this project. Also, the author thanks F. Nevarez for SPF testing, L. Holmes for part forming, M. Calabrese for metallographic support, Dr. R. Crooks for TEM, and Dr. A. Ghosh for helpful discussions.

\section{References}

1. H.W. Hayden, R.C. Gibson, H.F. Merrick and J.H. Brophy, "Superplasticity in the Ni-Fe-Cr System," Trans. ASM 60, 3-14 (1967).

2. J.E. Coyne and W.H. Couts, Ir., High-Temperature Alloys for Gas Turbines (Reidell Pub. Co., 1982), pp. 839-852.

3. W.T. Chandler, A.K. Ghosh and M.W. Mahoney, "Superplastic Forming and Diffusion Bonding of Inconel 718," J. Spacecraft and Rockets 21 (1), 61-64 (1984).

4. J.K. Gregory, J.C. Gibeling and W.D. Nix, "High-Temperature Deformation of Ultra-Fine-Grained Oxide Dispersion-Strengthened Alloys," Met. Trans. 16A, 777787 (1985).

5. J.B. Moore, J. Tequesta and R.L. Athey, "Fabrication Method for the High-Temperature Alloys," U.S. Patent 3,519,503 (July 1970). 
6. M.W. Mahoney and R. Crooks, "Superplastic Forming of Inconel 718," Proc. 117th Annual AIME Meeting, Superplasticity in Aerospace Symp. (Jan 1988), eds., H.C. Heikkenen and T.R. McNelley, 331-344, Jan. 1988.

7. W.A. Backofen, I.R. Turner and D.H. Avery, "Superplasticity in an Al-Zn Alloy," Trans. ASM 57, 980-990 (1964).

8. T.T. Bales and J.M. Shinn, "An Investigation of the Use of Post-Forming Pressure to Reduce Cavitation in Superplastically Formed 7475 Aluminum," Proc. AIME 117 th Annual Meeting on Superplasticity in Aerospace, Phoenix, AZ, Jan. 25, 1988, eds., T. McNelley and C. Heikkenen, to be published.

9. C.M. Packer, R.H. Johnson and O.D. Sherby, "Evidence for the Importance of Crystallographic Slip During Superplastic Deformation of Eutectic Zinc-Aluminum," Trans. AIME 242, 2485 (1968).

10. R.H. Johnson, C.M. Packer, L. Anderson and O.D. Sherby, "Microstructure of Superplastic Alloys," Phil. Mag. 18, 1309 (1968).

11. T. Sakai and J.J. Jonas, "Dynamic Recrystallization: Mechanical and Microstructural Considerations," Acta. Metall. 32, 189-204 (1984).

12. A.K. Ghosh and R. Raj, "The Evolution of Grain Size Distribution During Superplastic Deformation," Superplasticity, e.d, B. Baudelet and M. Suery (Paris, France, Centre National de la Recherche Scientifique, 1985), 11.1-11.19. 